\title{
Validation of the Appendicitis Inflammatory Response (AIR) Score
}

\author{
Manne Andersson ${ }^{1,2} \cdot$ Blanka Kolodziej $^{3}$ - Roland E. Andersson ${ }^{1,2}$ (D)
}

Accepted: 20 February 2021 / Published online: 6 April 2021

(C) The Author(s) 2021

\begin{abstract}
Background Patients with suspicion of appendicitis present with a wide range of severity. Score-based risk stratification can optimise the management of these patients. This prospective study validates the Appendicitis Inflammatory Response (AIR) score in patients with suspicion of appendicitis.

Method Consecutive patients over the age of five with suspicion of appendicitis presenting at 25 Swedish hospital's emergency departments were prospectively included. The diagnostic properties of the AIR score are estimated.

Results Some 3878 patients were included, 821 with uncomplicated and 724 with complicated appendicitis, 1986 with non-specific abdominal pain and 347 with other diagnoses. The score performed better in detecting complicated appendicitis (ROC area 0.89 (95\% confidence interval (CI) 0.88-0.90) versus 0.83 (CI 0.82-0.84) for any appendicitis, $p<0.001$ ), in patients below age 15 years and in patients with $>47 \mathrm{~h}$ duration of symptoms (ROC area 0.93 , CI $0.90-0.95$ for complicated and 0.87 , CI $0.84-0.90$ for any appendicitis in both categories). Complicated appendicitis is unlikely at AIR score $<4$ points (Negative Predictive Value 99\%, CI 98-100\%). Appendicitis is likely at AIR score $>8$ points, especially in young patients (positive predictive value (PPV) 96\%, CI 90-100\%) and men (PPV 89\%, CI 84-93\%).

Conclusions The AIR score has high sensitivity for complicated appendicitis and identifies subgroups with low probability of complicated appendicitis or high probability of appendicitis. The discriminating capacity is high in children and patients with long duration of symptoms. It performs equally well in both sexes. This verifies the AIR score as a valid decision support.

Trial registration number

https://clinicaltrials.gov/ct2/show/NCT00971438
\end{abstract}

Roland E. Andersson

roland.andersson@rjl.se

1 Department of Biomedical and Clinical Sciences, Faculty of Health Sciences, Linköping University, Linköping, Sweden

2 Department of Surgery, County Hospital Ryhov, 55185 Jönköping, Sweden

3 Department of Pathology, County Hospital Ryhov, County Council of Jönköping, Jönköping, Sweden

\section{Introduction}

In unselected patients with suspicion of acute appendicitis, the prevalence is typically about $30 \%$ and the clinical presentation varies from a mild to an overt septic condition. The management of these patients is resource consuming. Non-productive admissions and surgical explorations are common, indicating a need for improvement $[1,2]$.

The clinical diagnosis is the basis for the management but is commonly a non-systematic and subjective assessment of history, symptoms and signs, eventually 
supplemented by laboratory tests. Diagnostic imaging is increasingly used but is not universally available in all settings and its optimal role is controversial. As routine imaging may give high rates of false positive and false negatives in groups of patients with low and high prevalence of appendicitis, respectively, the use of imaging should be tailored to the patients pre-test probability of appendicitis [3-5]. Selective use of CT is also motivated to reduce ionising radiation exposure and potential risk of cancer induction [6]. Low dose CT or staged imaging, starting with ultrasound and using CT only in patients with unclear ultrasound result, may decrease this risk [7, 8].

Risk-stratification based on a clinical score can be used to optimise the selection of patients for urgent surgical evaluation, diagnostic imaging, in-patient or out-patient observation. In a previous study, the prospective implementation of an algorithm based on the Appendicitis Inflammatory Response (AIR) score (Fig. 1) led to a reduction in unnecessary hospital admissions and a decreased use of diagnostic imaging [9, 10]. The present study is an in-depth validation of the AIR-score. We hypothesise that the AIR-score is a suitable decision support for the management of patients with suspected appendicitis.

\section{Patients and Methods}

\section{Study design and setting}

The present study is based on data from the STRAPPSCORE study (STRuctured management of patients with suspicion of APPendicitis using a clinical SCORE) which is a prospective interventional multicentre study with 25 participating Swedish hospitals (eight university hospitals, eight county hospitals, and nine general hospitals) including patients between September 2009 and January 2012. The main report from the STRAPPSCORE study has been published elsewhere [10].

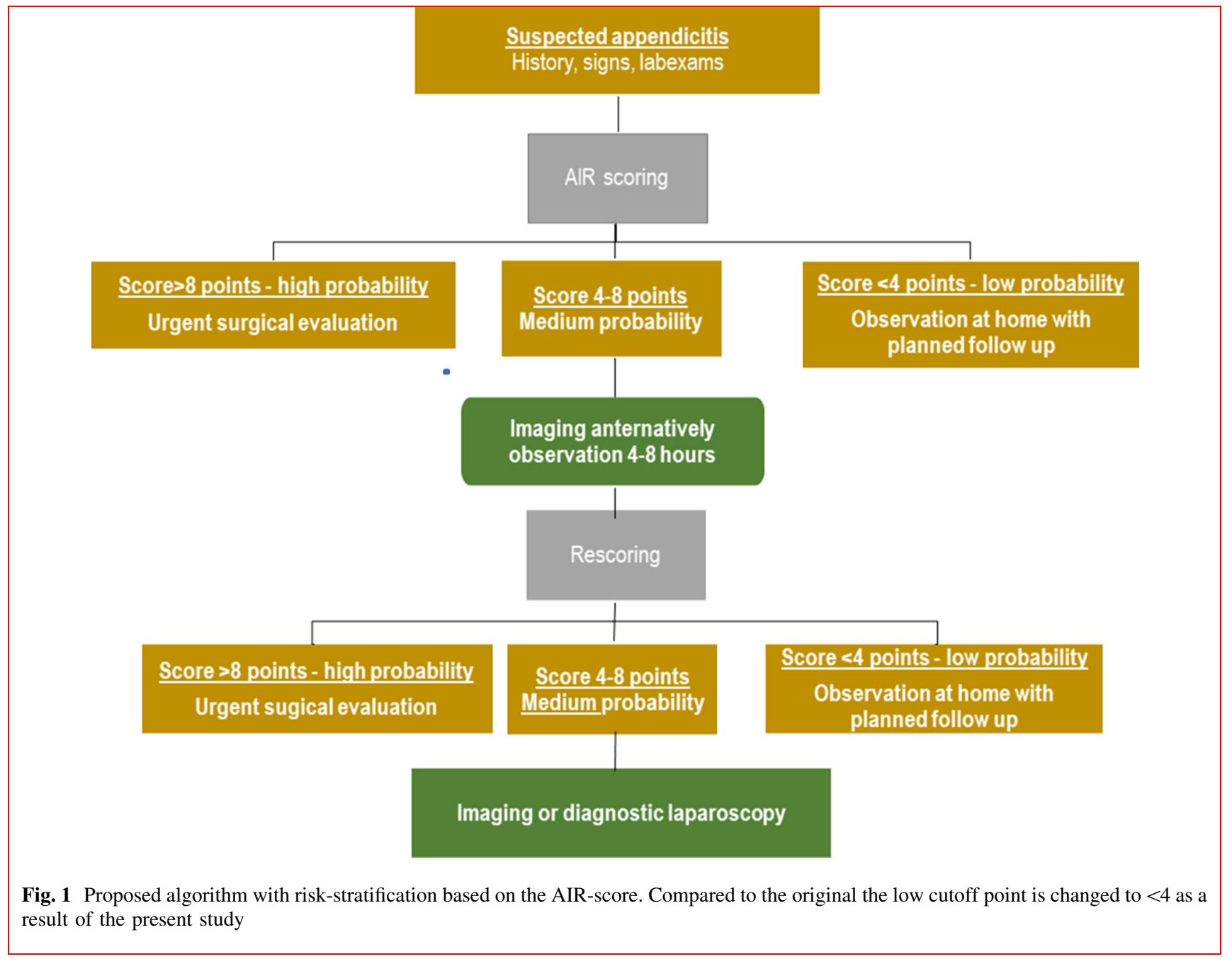




\section{Data collection}

Consecutive patients aged over five years presenting with low abdominal pain of less than 5 days duration suggestive of appendicitis were considered for inclusion. The AIR score parameters (right lower quadrant pain, intensity of rebound tenderness or muscular defence, CRP concentration, WBC count, proportion of neutrophils, body temperature, and history of vomiting) were prospectively registered. Duration of symptoms and the level of experience of the physician managing the patient on arrival were noted. The use of diagnostic imaging (ultrasound, US, and/ or computerised tomography, CT), any surgical intervention, per-operative and discharge diagnoses, and use of antibiotics, were noted at the discharge.

The study was conducted in two phases. During the baseline phase, the AIR score parameters were recorded prospectively but the score was not determined, and the patients were managed according to the local standards. During the intervention phase, the AIR score sum is calculated (Table 1), and the physician was instructed to follow the proposed algorithm (Fig. 1). The present study includes the AIR score sum from both phases.

The AIR score sum defines three groups: low probability ( $<5$ points), medium probability (5-8 points), and high probability ( $>8$ points) [9]. At high probability the algorithm recommends immediate evaluation for eventual

Table 1 Appendicitis Inflammatory Response (AIR) score, 0-12 points

\begin{tabular}{ll}
\hline Item & Scoring point \\
\hline Vomiting & 1 \\
Pain in right inferior fossa & 1 \\
Rebound tenderness or muscular defence & \\
Light & 1 \\
Medium & 2 \\
Strong & 3 \\
Body temperature $\geq 38.5{ }^{\circ} \mathrm{C}$ & 1 \\
White blood cell count & \\
$10.0-14.9 * 109 / \mathrm{L}$ & 1 \\
$\geq 15.0 * 109 / \mathrm{L}$ & 2 \\
Proportion polymorphonuclear leucocytes & \\
$70-84 \%$ & 1 \\
$\geq 85 \%$ & 2 \\
C-reactive protein concentration & \\
$10-49 \mathrm{mg} / \mathrm{L}$ & 1 \\
$\geq 50 \mathrm{mg} / \mathrm{L}$ & 2
\end{tabular}

Seven variables are assessed and scored accordingly. After the revision proposed in this report a score $0-3$ points suggest low probability, a score 4-8 medium probability and a score 9-12 high probability abdominal exploration. At low probability outpatient management with a planned follow-up within $24 \mathrm{~h}$ is proposed. In the STRAPSCORE study, the medium probability group was randomised to immediate imaging or a period of in-hospital observation followed by rescoring and selective imaging.

\section{Diagnosis}

Participating surgeons were instructed to send all removed appendices for histopathological examination. All participating pathologists were blinded to the AIR-score sum and instructed to report about the presence or absence of transmural infiltration of neutrophils and transmural tissue necrosis. If a collection of pus surrounding the appendix or a perforation with free peritonitis was identified during surgery, the appendix is considered perforated. Patients that were diagnosed with an appendiceal abscess or phlegmone by imaging and treated with antibiotics and eventual drainage were classified as complicated appendicitis. The criteria for uncomplicated appendicitis is transmural neutrophil invasion. Complicated appendicitis is defined as presence of transmural necrosis or perforation. To obtain a standardised histopathological diagnosis, the excised appendices from patients in the high and low probability groups were re-examined by one consultant pathologist. Patients with other, non-appendicitis diagnoses, are included among the non-appendicitis group in all the following estimations.

All computerised tomography (CT) scans have been reexamined by radiologists blinded to the original report. A diagnosis of appendicitis is accepted also for non-operated patients when an appendicitis diagnosis was consistently reported in both the original report and the repeat examination of the CT study.

\section{Follow-up}

All patients were followed up for a minimum of 30 days through linkage with the Swedish national patient register using the Swedish national identification number, unique to all Swedish citizens [11]. Discharged patients with an operation for appendicitis at any Swedish hospital within seven days after the index admission are considered a missed appendicitis, and the outcome of the patient was changed according to the appendectomy diagnosis.

\section{Statistical analysis}

\section{Diagnostic properties of the AIR score}

We use the receiver operating characteristic (ROC) area to analyse the discriminating capacity for any appendicitis 
(i.e. uncomplicated or complicated appendicitis) vs no appendicitis, and for complicated appendicitis vs no appendicitis. We estimate sensitivity, specificity, and predictive values at each score point and at the low and high cut offs, respectively. We report results for pre-defined subgroups of patients according to age, sex, duration of symptoms, and competence of the physician.

\section{Missing values}

The dataset contained missing values. Little's test for the assumption of covariate-dependent missingness was not significant suggesting that multiple imputation is applicable to avoid biased results [12]. We used multiple chained equation imputation to replace missing values [13]. Patients with missing values in more than two scoring variables were excluded.

Categorical variables were compared by means of the $\chi^{2}$ test, and continuous variables using t-test or Mann-Whitney U test as appropriate. Significance is defined as a twotailed $p$-value $<0.05$ for all comparisons. The data were analysed using Stata 15, StataCorp. 2015. Stata Statistical Software: Release 15. College Station, TX: StataCorp LP.

The study was approved by the Linköping University regional ethics committee (M15-09 and 2011/375-32) and was registered at ClinicalTrials.gov (NCT00971438).
Results

\section{Study population}

A total of 4279 patients were included in the STRAPPSCORE study (Fig. 2). Some 401 patients with more than two missing AIR score parameters were excluded, leaving 3878 patients for analysis. (Table 2) Patients with nonspecific abdominal pain (NSAP) was the largest group (1986, 51.2\%). Some 821 (21.2\%) had uncomplicated and $724(18.7 \%)$ complicated appendicitis and $347(8.9 \%)$ had other diagnoses. Appendicitis was most common among men and NSAP, and other diagnoses were more common among women.

One or two missing AIR score parameters were subsequently imputed in 985 (25.4\%) patients. Missing values were most common for the proportion of neutrophils ( $n=569$ or $15 \%$ of total) followed by body temperature ( $n=321$ or $8 \%$ of total).

\section{The diagnostic performance of the AIR score}

\section{ROC area}

The AIR score has a higher discriminating capacity for complicated appendicitis (ROC area 0.89 vs. 0.83 for any

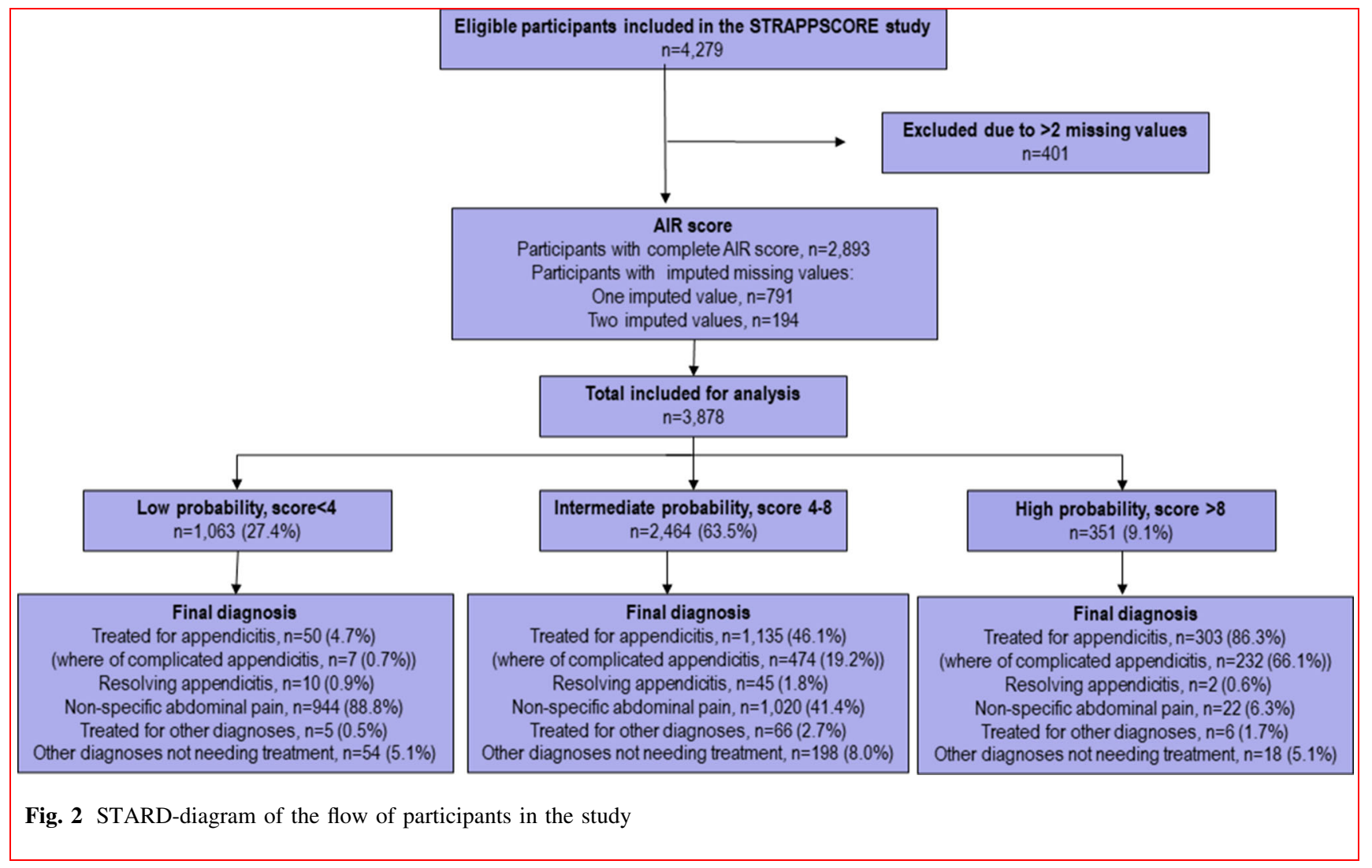


Table 2 Demography and characteristics of the included patients with suspicion of appendicitis

\begin{tabular}{llllll}
\hline Characteristic & Total & Abdominal pain & $\begin{array}{l}\text { Non-specific } \\
\text { Uncomplicated }\end{array}$ & $\begin{array}{l}\text { Appendicitis } \\
\text { Complicated }\end{array}$ & $\begin{array}{l}\text { Other } \\
\text { Diagnoses }\end{array}$ \\
\hline Numbers (\%) & 3878 & $1986(51.2)$ & $821(21.2)$ & $724(18.7)$ & $347(8.9)$ \\
Age, median (IQR) & $26.1(18.2-40.3)$ & $23.4(17.6-34.9)$ & $26.5(18.5-38.7)$ & $34.2(19.9-50.2)$ & $34.7(21.5-54.1)$ \\
Males (\%) & $1802(46.5)$ & $751(37.8)$ & $483(58.8)$ & $423(58.4)$ & $145(41.8)$ \\
Females (\%) & $2076(53.5)$ & $1235(62.2)$ & $338(41.2)$ & $301(41.6)$ & $202(58.2)$ \\
Duration of symptoms, hours (IQR) & $24(12-48)$ & $24(10-48)$ & $20(12-30)$ & $24(14-48)$ & $24(12-48)$ \\
One missing value & $791(20.4 \%)$ & $401(20.2)$ & $176(21.4)$ & $138(19.1)$ & $76(21.9)$ \\
Two missing values & $194(5.0 \%)$ & $120(6.0)$ & $38(4.6)$ & $29(4.0)$ & $7(2.0)$ \\
Imaging & $1788(37.8)$ & $606(30.5)$ & $496(60.4)$ & $412(56.9)$ & $274(78.9)$ \\
\hline
\end{tabular}

appendicitis, $p<0.001$ ) (Table 3). For the diagnosis of any appendicitis, it performs best in patients below age 15 years (ROC area 0.87 ) and in patients with over $47 \mathrm{~h}$ duration of symptoms (ROC area 0.86). The corresponding results for complicated appendicitis are 0.92 and 0.93 . It performs equally well in both sexes and irrespective of the examiner's competence.

\section{Validation of the cut-off points}

In the original design study the AIR score obtained a sensitivity of $100 \%$ at the low cut-off point $\geq 5$. In the present study, the sensitivity for complicated appendicitis is $96.1 \%$ at this cut-off point (Table 4 ). An adjustment of the low cut-off point to $\geq 4$ points, which gives a sensitivity for complicated appendicitis of $99.0 \%$, is therefore motivated. For the high probability group, the present study obtains an almost identical specificity at the high cut-off point $\geq 9(98.0 \%$ vs. $99.0 \%)$.

Sensitivity, specificity, and predictive values

Low probability group The low probability group aims to rule out patients with advanced appendicitis to safely practice outpatient observation and planned repeat examination. Some 1063 patients $(27.4 \%)$ were classified as low probability with AIR-score $<4$ points. Seven patients $(0.7 \%)$ had a final diagnosis of complicated appendicitis and another $4.7 \%$ had appendectomy for appendicitis in this group (Table 5). This corresponds to a sensitivity of 99\% and a Negative Predictive Value (NPV) of $99 \%$ for complicated appendicitis, and a sensitivity of $96 \%$ and NPV of $94 \%$ for any appendicitis (Table 6). The NPV for complicated appendicitis was higher in women (100\% vs. $98 \%$ for men, $p=0.042$ ) but did not differ depending on age, examiners competence or duration of symptoms (Table 6). One patient in this group needed surgical treatment for other diagnosis (volvulus), and 23 patients (2.2\%) had a non-therapeutic exploration. Ten patients with CT verified appendicitis resolved without treatment.

\section{High probability group}

The aim for the high probability group is to select patients for urgent surgical evaluation for eventual operation avoiding negative appendectomy. Some 351 patients $(9.1 \%)$ are classified to the high probability group with AIR-score $>8$, of which $232(66 \%)$ had complicated appendicitis $(32.5 \%$ of all complicated appendicitis) (Table 5). The specificity for all appendicitis is $98 \%$ overall and slightly higher in children under age 15 years $(99 \%)$ and patients with short duration of symptoms (99\%). The positive predictive value (PPV) for any appendicitis is $86 \%$. (Table 7) Twenty-four patients $(6.8 \%)$ had another diagnosis. Two of them had surgical treatment-one for Crohns disease and one for rectal cancer. Thirteen patients $(3.7 \%)$ had a non-productive abdominal exploration.

\section{Discussion}

This large multicenter study verifies the AIR-score as a valid and reproducible instrument with high discriminating capacity especially for advanced appendicitis. It defines groups of patients with low, medium, and high probability of appendicitis with high sensitivity and specificity. A large proportion $(47.5 \%)$ of the patients without appendicitis were assigned to the low risk group and $32.5 \%$ of all complicated appendicitis were assigned to the high risk group, showing its utility as basis for a safe risk-adapted management that can help in identifying patients in need of urgent surgical evaluation and minimising unproductive hospital admissions and abdominal explorations. 
Table 3 Discriminating capacity of the AIR-score overall, in subsets of patients and according to the examiner's competence, expressed as the ROC area

\begin{tabular}{|c|c|c|c|c|c|c|}
\hline \multirow[t]{2}{*}{ Characteristics } & \multicolumn{3}{|l|}{ ROC area* } & \multicolumn{3}{|l|}{ ROC area* } \\
\hline & Appendicitis & $95 \% \mathrm{CI}$ & $p$-value & Complicated & $95 \% \mathrm{CI}$ & $p$-value \\
\hline All patients & 0.83 & $0.82-0.84$ & & 0.89 & $0.88-0.90$ & $<0.001 * *$ \\
\hline Patients sex & & & 0.18 & & & 0.16 \\
\hline Women & 0.84 & $0.82-0.85$ & & 0.90 & $0.88-0.91$ & \\
\hline Men & 0.82 & $0.80-0.84$ & & 0.88 & $0.86-0.90$ & \\
\hline Patients age & & & 0.001 & & & $<0.001$ \\
\hline$<15$ years & 0.87 & $0.84-0.90$ & & 0.93 & $0.90-0.95$ & \\
\hline 15-39 years & 0.83 & $0.81-0.84$ & & 0.89 & $0.88-0.91$ & \\
\hline$\geq 40$ years & 0.79 & $0.76-0.82$ & & 0.84 & $0.82-0.87$ & \\
\hline Duration of symptoms & & & 0.001 & & & $<0.001$ \\
\hline$<12 \mathrm{~h}$ & 0.80 & $0.77-0.83$ & & 0.84 & $0.80-0.88$ & \\
\hline $12-23 \mathrm{~h}$ & 0.81 & $0.78-0.84$ & & 0.86 & $0.83-0.89$ & \\
\hline $24-47 \mathrm{~h}$ & 0.83 & $0.80-0.85$ & & 0.89 & $0.86-0.91$ & \\
\hline$>47 \mathrm{~h}$ & 0.87 & $0.85-0.89$ & & 0.93 & $0.91-0.95$ & \\
\hline Examiners competence & & & 0.61 & & & 0.15 \\
\hline Interns & 0.82 & $0.80-0.84$ & & 0.88 & $0.86-0.90$ & \\
\hline Residents & 0.83 & $0.81-0.85$ & & 0.90 & $0.88-0.92$ & \\
\hline Specialists & 0.82 & $0.79-0.85$ & & 0.86 & $0.83-0.90$ & \\
\hline
\end{tabular}

*ROC is Receiver Operating Curve

${ }^{* *} p$-value for the comparison of the ROC are for all appendicitis and complicated appendicitis

Table 4 Distribution of patients over the AIR-score according to the final diagnosis, and corresponding diagnostic characteristics at all cut-off points

\begin{tabular}{|c|c|c|c|c|c|c|c|c|c|}
\hline \multirow{3}{*}{$\begin{array}{l}\text { Score } \\
\text { points }\end{array}$} & \multicolumn{5}{|c|}{ Numbers according to diagnosis } & \multirow{3}{*}{$\begin{array}{l}\text { Cut off } \\
\text { points }\end{array}$} & & & \multirow{3}{*}{$\begin{array}{l}\text { Specificity } \\
\text { Appendicitis } \\
(\%)\end{array}$} \\
\hline & \multirow[t]{2}{*}{ NSAP } & \multicolumn{2}{|l|}{ Appendicitis } & \multirow{2}{*}{$\begin{array}{l}\text { Other } \\
\text { diagnoses }\end{array}$} & \multirow[t]{2}{*}{ Total } & & \multicolumn{2}{|l|}{ Sensitivity } & \\
\hline & & Uncomplicated & Complicated & & & & $\begin{array}{l}\text { Appendicitis } \\
(\%)\end{array}$ & $\begin{array}{l}\text { Complicated } \\
(\%)\end{array}$ & \\
\hline 0 & 60 & 0 & 0 & 2 & 62 & $\geq 0$ & 100.0 & 100.0 & 0.0 \\
\hline 1 & 195 & 2 & 1 & 6 & 204 & $\geq 1$ & 100.0 & 100.0 & 2.7 \\
\hline 2 & 323 & 12 & 0 & 21 & 356 & $\geq 2$ & 99.8 & 99.9 & 11.3 \\
\hline 3 & 366 & 39 & 6 & 30 & 441 & $\geq 3$ & 99.0 & 99.9 & 26.0 \\
\hline 4 & 364 & 83 & 25 & 45 & 517 & $\geq 4$ & 96.1 & 99.0 & 43.0 \\
\hline 5 & 292 & 156 & 75 & 62 & 585 & $\geq 5$ & 89.1 & 95.6 & 60.5 \\
\hline 6 & 210 & 183 & 114 & 64 & 571 & $\geq 6$ & 74.2 & 85.2 & 75.7 \\
\hline 7 & 104 & 160 & 137 & 52 & 453 & $\geq 7$ & 55.0 & 69.5 & 87.4 \\
\hline 8 & 50 & 116 & 131 & 41 & 338 & $\geq 8$ & 35.7 & 50.6 & 94.1 \\
\hline 9 & 15 & 55 & 116 & 15 & 201 & $\geq 9$ & 19.7 & 32.5 & 98.0 \\
\hline 10 & 6 & 12 & 76 & 5 & 99 & $\geq 10$ & 8.7 & 16.4 & 99.3 \\
\hline 11 & 1 & 3 & 39 & 1 & 44 & $\geq 11$ & 3.0 & 5.9 & 99.8 \\
\hline 12 & 0 & 0 & 4 & 3 & 7 & $\geq 12$ & 0.3 & 0.6 & 99.9 \\
\hline Total & 1986 & 821 & 724 & 347 & 3878 & & & & \\
\hline
\end{tabular}

A new low cut-off point $>=4$ is proposed as the original cut-off point $>=5$ has insufficient sensitivity for complicated appendicitis 
Table 5 Distribution of outcome in the three risk groups according to the AIR score

\begin{tabular}{|c|c|c|c|c|c|c|}
\hline \multirow[t]{2}{*}{ Outcome } & \multicolumn{6}{|c|}{ AIR score } \\
\hline & \multicolumn{2}{|c|}{ 0-4 points No. $\%$} & \multicolumn{2}{|c|}{ 5-8 points No. $\%$} & \multicolumn{2}{|c|}{ 9-12 points No. \% } \\
\hline \multicolumn{7}{|l|}{ Non-specific abdominal pain } \\
\hline No treatment & 926 & 87.1 & 870 & 35.3 & 8 & 2.3 \\
\hline Antibiotics & 2 & 0.2 & 29 & 1.2 & 4 & 1.1 \\
\hline Negative appendectomy & 16 & 1.5 & 121 & 4.9 & 10 & 2.8 \\
\hline \multicolumn{7}{|l|}{ Appendicitis } \\
\hline No treatment & 10 & 0.9 & 45 & 1.8 & 2 & 0.6 \\
\hline Antibiotics & 0 & 0 & 30 & 1.2 & 7 & 2.0 \\
\hline Appendectomy & 50 & 4.7 & 1105 & 44.8 & 296 & 84.3 \\
\hline (where of complicated appendicitis) & 7 & 0.7 & 474 & 19.2 & 232 & 66.1 \\
\hline \multicolumn{7}{|l|}{ Other diagnoses } \\
\hline No treatment & 47 & 4.4 & 182 & 7.4 & 15 & 4.3 \\
\hline Antibiotics & 4 & 0.4 & 44 & 1.8 & 4 & 1.1 \\
\hline Treated with surgery & 1 & 0.1 & 22 & 0.9 & 2 & 0.6 \\
\hline Non-therapeutic abdominal exploration & 7 & 0.7 & 16 & 0.6 & 3 & 0.9 \\
\hline Total non-therapeutic abdominal exploration & 23 & 2.2 & 137 & 5.6 & 13 & 3.7 \\
\hline Imaging & 230 & 21.6 & 1370 & 55.6 & 166 & 47.3 \\
\hline Total & 1063 & 100 & 2464 & 100 & 351 & 100 \\
\hline
\end{tabular}

The total number of non-therapeutic abdominal explorations includes all negative appendectomies and all abdominal explorations for other diagnosis not leading to any change in treatment

Table 6 Diagnostic properties at the low probability zone

\begin{tabular}{|c|c|c|c|c|c|c|}
\hline \multirow[t]{3}{*}{ Characteristics } & \multicolumn{6}{|c|}{ AIR score $0-4$} \\
\hline & \multicolumn{6}{|c|}{ Complicated appendicitis } \\
\hline & NPV & $95 \% \mathrm{CI}$ & $p$-value & Sensitivity & $95 \% \mathrm{CI}$ & $p$-value \\
\hline All patients & 99 & $98-100$ & & 99 & $98-100$ & \\
\hline Patients sex & & & 0.042 & & & 0.48 \\
\hline Women & 100 & 99-100 & & 99 & $98-100$ & \\
\hline Men & 98 & $97-100$ & & 98 & $97-100$ & \\
\hline Patients age & & & 0.44 & & & 0.85 \\
\hline$<15$ years & 99 & $97-100$ & & 98 & 94-100 & \\
\hline $15-39$ years & 99 & $98-100$ & & 98 & $97-100$ & \\
\hline$\geq 40$ years & 99 & $97-100$ & & 99 & $98-100$ & \\
\hline Duration of symptoms & & & 0.46 & & & 0.10 \\
\hline$<12 \mathrm{~h}$ & 99 & $98-100$ & & 97 & $94-100$ & \\
\hline $12-23 \mathrm{~h}$ & 98 & $96-100$ & & 98 & $96-100$ & \\
\hline $24-47 \mathrm{~h}$ & 99 & $98-100$ & & 100 & $99-100$ & \\
\hline$>47 \mathrm{~h}$ & 99 & $98-100$ & & 99 & $97-100$ & \\
\hline Examiners competence & & & 0.52 & & & 0.87 \\
\hline Interns & 99 & $98-100$ & & 99 & $97-100$ & \\
\hline Residents & 99 & $98-100$ & & 99 & $98-100$ & \\
\hline Specialists & 98 & $96-100$ & & 98 & $95-100$ & \\
\hline
\end{tabular}

NPV and sensitivity for complicated appendicitis is presented as not missing complicated appendicitis is most important to safely practice observation 
Table 7 Diagnostic properties in the high probability zone

\begin{tabular}{|c|c|c|c|c|c|c|}
\hline \multirow[t]{3}{*}{ Characteristics } & \multicolumn{6}{|c|}{ AIR score $9-12$} \\
\hline & \multicolumn{6}{|c|}{ Any appendicitis } \\
\hline & PPV & $95 \% \mathrm{CI}$ & $p$-value & Specificity & $95 \% \mathrm{CI}$ & $p$-value \\
\hline All patients & 86 & $83-90$ & & 98 & 97-99 & \\
\hline Patients sex & & & 0.25 & & & 0.31 \\
\hline Women & 84 & $78-90$ & & 98 & $97-99$ & \\
\hline Men & 89 & $84-93$ & & 98 & $97-99$ & \\
\hline Patients age & & & 0.18 & & & $<001$ \\
\hline$<15$ years & 96 & $90-100$ & & 99 & $98-100$ & \\
\hline $15-39$ years & 86 & $81-92$ & & 99 & $98-99$ & \\
\hline$\geq 40$ years & 83 & $76-89$ & & 95 & 94-97 & \\
\hline Duration of symptoms & & & 0.74 & & & 0.047 \\
\hline$<12 \mathrm{~h}$ & 84 & & $71-98$ & 99 & $98-100$ & \\
\hline $12-23 \mathrm{~h}$ & 89 & & $81-97$ & 98 & $97-100$ & \\
\hline $24-47 \mathrm{~h}$ & 86 & & $79-93$ & 97 & $95-98$ & \\
\hline$>47 \mathrm{~h}$ & 87 & & $80-93$ & 98 & $96-99$ & \\
\hline Examiners competence & & & 0.49 & & & 0.23 \\
\hline Interns & 87 & $81-93$ & & 98 & $97-99$ & \\
\hline Residents & 88 & $82-94$ & & 98 & $97-99$ & \\
\hline Specialists & 83 & $74-92$ & & 97 & 95-99 & \\
\hline
\end{tabular}

PPV and Specificity for any appendicitis is given as the focus is avoiding negative appendectomy

The clinical diagnosis and diagnostic imaging are the pillars in modern management of patients with suspicion of appendicitis, but the optimal management algorithm is still controversial. Routine imaging in unselected patients is not recommended because of the high frequency of false-positive and false-negative diagnosis in patients with low or high prevalence of appendicitis, respectively [3-5, 14]. Routine CT scanning in unselected patients with a mean prevalence of $32 \%$ will give an estimated PPV of only $70 \%$ [7]. Imaging will thus over diagnose appendicitis in patients with a low clinical probability and cannot rule out appendicitis in patients with high clinical probability. A meta-analysis of the cost-effectiveness of imaging strategies in children concluded that imaging is not cost-effective for patients with a risk of appendicitis $<16 \%$ or $>95 \%$ and that the imaging approach should be tailored on the basis of a patient's pretest probability of appendicitis [15].

Many algorithms propose a risk-differentiated strategy but do not specify how the risk can be determined or only give a general reference to "typical history and clinical findings". Clinical scoring systems are instruments to determine the probability of appendicitis in the individual patient [16]. The AIR score is based on mainly objective inflammatory markers which may explain the high reproducibility of the score in different settings and irrespective of the experience of the examiner. The AIR score has been recommended in two recent reviews with a reference to its usability and diagnostic performance $[16,17]$. It has been compared with the Alvarado score in 11 studies and performed better in 10 of them [1, 18-26]. It has been prospectively validated in patients with suspicion of appendicitis in 12 previous studies $[1,10,18-21,23,26-30]$, in most cases with similar results to the present study.

The AIR score was designed with a focus on ruling out patients with complicated appendicitis from the low risk group. These patients can safely be observed as outpatients with planned repeat examination. The few cases with complicated appendicitis in this group $(0.7 \%)$ were diagnosed at the repeat examination after observation. A large proportion of the patients can thus be saved the costs of further diagnostic workup or hospital admission. This may also allow some patients with mild appendicitis to resolve spontaneously with no treatment [31].

Another aim was to identify patients with high probability of appendicitis that need an urgent surgical evaluation and a probable abdominal exploration. Some $9.2 \%$ of the patients are classified as high probability with a prevalence of appendicitis of $84 \%$, of which the majority had complicated appendicitis $(66 \%)$. One-third of all 
patients with complicated appendicitis was assigned to this group. The PPV was very high in patients aged $<15$ years $(96 \%)$ and in men $(89 \%)$. This may motivate an abdominal exploration with no further diagnostic work-up as imaging cannot rule out appendicitis in patients with high probability of appendicitis and a differential diagnosis is less likely. In women and patients aged $\geq 40$ years, a diagnostic imaging may however be indicated due to the lower PPV ( $84 \%$ and $83 \%$, respectively).

Imaging can identify differential diagnoses which may need further treatment or work-up. This is more common in older patients. In the present study, one patient with alternative diagnosis needing surgery was diagnosed in the low probability group and two patients in the high probability group.

Monitored in-hospital observation with repeat examination is the traditional management that has stand the test of time. In the intervention part of the STRAPPSCORE study, the patients with an intermediate AIR-score were randomised to early imaging or a period of observation followed by repeat scoring and selective imaging. We found no advantage of routine diagnostic imaging compared with observation and selective imaging [10].

The strength of the present study is its size and prospective, multicentre design, which verifies the validity of the AIR score in various settings and in the hands of physicians with varying experience. The score performed better in patients below age 15 years and in women, which are regarded as especially challenging. This support that the AIR score is applicable to all patients with suspected appendicitis irrespective of age or sex.

A weakness is the missing values of which the proportion of neutrophils was the most frequent. This reflects the logistic difficulties when introducing new methods in emergency departments with involvement of many actors that are constantly changing over time. The reported estimates should however be valid with low probability of bias as we used multiple imputation [32].

The data were collected between 2009 and 2012. Some may question if these data are still valid. However, the criteria for the appendicitis diagnosis (transmural neutrophil invasion or imaging suggesting appendiceal abscess or phlegmon) has not changed since 2012. The seven variables used in the AIR-score are still all used routinely to the same extent as in 2012. There is no new laboratory examination reported that have replaced the variables included in the score. The association of the AIR-score with the appendicitis diagnosis have therefore not been influenced by the time that has passed. The sensitivity, specificity, and discriminating capacity for at least complicated appendicitis should be valid also today in all the subgroup analyses.
However, the quality of diagnostic imaging has improved since 2012 and its usage has increased. As a consequence more cases of mild appendicitis that previously was allowed to resolve undiagnosed are now detected, as shown by an increasing incidence rate of uncomplicated appendicitis in recent decades. In the previous report of the randomised trial comparing immediate imaging with an observation period followed by selective imaging, we thus found more patients diagnosed with mild appendicitis in the imaging arm which may have resolved undiagnosed in the observation arm [10]. As we have followed up all cases, we can with confidence claim that we have not missed any patient needing treatment.

The effect of this could be a lower sensitivity for appendicitis at the low cut off. However, throughout the manuscript, we emphasise that the aim is to identify patients with complicated appendicitis with high sensitivity, whereas we do not aim at ruling out patients with mild appendicitis at the low cut-off point. We therefore suggest planned re-examination of the patients with low probability. We think this is certainly valid also in this era.

This large external validation of the AIR score verify the validity and replicability of the AIR score but shows a need to adjust the originally proposed cut-off point for the low probability. It performed especially well in children and women which are regarded as the most challenging groups for diagnosing appendicitis. The score can be used as a decision support for a risk-stratified management adapted to the probability of appendicitis. This may help minimising unproductive hospital admissions and abdominal explorations and in selection of patients for urgent surgical evaluation and diagnostic imaging.

Acknowledgements STRAPPSCORE studygroup: Roland Andersson, Manne Andersson, Blanka Kolodziej, Länssjukhuset Ryhov, Jönköping; Torbjörn Eriksson, Anders Ramsing, Värnamo sjukhus; Hans Ravn, Lina Hellman, Johanna Björkman, Höglandssjukhuset Eksjö; Hans Olof Håkansson, Tobias Lundström, Länssjukhuset Kalmar; Hilding Björkman, Patrik Johansson, Centrallasarettet Växjö; Ola Hjert, Ljungby Lasarett; Roger Edin, Anders Ekström, Cecilia Wenander, Varbergs Sjukhus; Conny Wallon, Per Andersson, Universitetssjukhuset, Linköping; Jessica Frisk, Norrköpings lasarett; Bengt Arvidsson, Rafael Lantz, Västerviks sjukhus; Göran Wallin, Åsa Wickberg, Universitetssjukhuset Örebro; Erik Stenberg, Lindesbergs Lasarett; Claes Erixon, Wilko Schmidt, Karlskoga Lasarett; Johanna Räntfors, Gunnar Göthberg, Drottning Silvias barn- och ungdomssjukhus, Johan Styrud, Khalid Elias, Danderyds Sjukhus, Lennart Boström, Gerold Kretschmar, Magnus Jonsson, Caroline Brav, Södersjukhuset; Ingemar Nilsson, Fariba Kamran, Capio St Görans sjukhus; Folke Hammarqvist, Karolinska Sjukhuset; Jan Rutqvist, Markus Almström, Astrid Lindgrens Barnsjukhus; Mats Hedberg, Veronica Lindh, Mora sjukhus; Anders Rosemar, Harald Wangberg, Jonas Gustafsson, Östra sjukhuset, Göteborg; Gunnar Neovius, Centralsjukhuset, Kristianstad; Claes Juhlin, Rolf Christofferson, Christopher Månsson, Akademiska sjukhuset, Uppsala; Tilman Zittel, Niklas Fagerström, Hudiksvall sjukhus. 
Funding Open access funding provided by Linköping University.. This study was supported by Futurum: The Academy for Health and Care Jönköping County Council, Sweden, and the Research Council of South-Eastern Sweden (FORSS). The study was approved by the Linköping University regional ethics committee (M15-09 and 2011/375-32). Informed consent was obtained from all individual participants included in the study.

\section{Compliance with Ethical Standards}

Conflict of interest The authors declare that they have no conflict of interest.

Open Access This article is licensed under a Creative Commons Attribution 4.0 International License, which permits use, sharing, adaptation, distribution and reproduction in any medium or format, as long as you give appropriate credit to the original author(s) and the source, provide a link to the Creative Commons licence, and indicate if changes were made. The images or other third party material in this article are included in the article's Creative Commons licence, unless indicated otherwise in a credit line to the material. If material is not included in the article's Creative Commons licence and your intended use is not permitted by statutory regulation or exceeds the permitted use, you will need to obtain permission directly from the copyright holder. To view a copy of this licence, visit http://creativecommons. org/licenses/by/4.0/.

\section{References}

1. Bhangu A (2020) Evaluation of appendicitis risk prediction models in adults with suspected appendicitis. $\mathrm{Br} \mathrm{J}$ Surg 107:73-86. https://doi.org/10.1002/bjs.11440

2. Andersson RE (2020) RIFT study and management of suspected appendicitis. Br J Surg 107:e207

3. Van RA, Bipat S, Zwinderman AH et al (2008) Acute appendicitis: meta-analysis of diagnostic performance of CT and purpose: methods: results: conclusion. Radiology 249:97-106

4. Terasawa T, Blackmore CC, Bent S, Kohlwes RJ (2004) Systematic review: computed tomography and ultrasonography to. Ann Intern Med 141:537-546

5. Giljaca V, Nadarevic T, Poropat G et al (2017) Diagnostic accuracy of abdominal ultrasound for diagnosis of acute appendicitis: systematic review and meta-analysis. World J Surg 41:693-700. https://doi.org/10.1007/s00268-016-3792-7

6. Power SP, Moloney F, Twomey M et al (2016) Computed tomography and patient risk: facts, perceptions and uncertainties. World J Radiol 8:902. https://doi.org/10.4329/wjr.v8.i12.902

7. Rud B, Vejborg TS, Rappeport ED et al (2019) Computed tomography for diagnosis of acute appendicitis in adults. Cochrane Database Syst Rev. https://doi.org/10.1002/14651858. CD009977.pub2

8. Krishnamoorthi R, Ramarajan N, Wang NE et al (2011) Effectiveness of a staged US and CT protocol for the diagnosis of pediatric appendicitis: reducing radiation exposure in the age of ALARA. Radiology 259:231-239. https://doi.org/10.1148/radiol. 10100984

9. Andersson M, Andersson RE (2008) The appendicitis inflammatory response score: a tool for the diagnosis of acute appendicitis that outperforms the Alvarado score. World J Surg. https:// doi.org/10.1007/s00268-008-9649-y

10. Andersson M, Kolodziej B, Andersson RE, STRAPPSCORE Study Group (2017) Randomized clinical trial of appendicitis inflammatory response score-based management of patients with suspected appendicitis. Br J Surg 104:1451-1461. https://doi.org/ 10.1002/bjs. 10637

11. Swedish National Board of Health and Welfare. National Swedish Patient Register No Title. https://www.socialstyrelsen. se/en/statistics-and-data/registers/register-information/thenational-patient-register/. Accessed 30 Jun 2012

12. Little RJA (1988) A test of missing completely at random for multivariate data with missing values. J Am Stat Assoc 83:1198-1202. https://doi.org/10.1080/01621459.1988.10478722

13. Schuetz CG (2008) Using neuroimaging to predict relapse to smoking: role of possible moderators and mediators. Int $\mathbf{J}$ Methods Psychiatr Res 17(Suppl 1):S78-S82. https://doi.org/10. $1002 / \mathrm{mpr}$

14. Weston AR, Jackson TJ, Blamey S (2005) Diagnosis of appendicitis in adults by ultrasonography or computed tomography: a systematic review and meta-analysis. Int J Technol Assess Health Care 21:368-379. https://doi.org/10.1017/S0266462305050488

15. Jennings R, Guo H, Goldin A, Wright DR (2020) Cost-effectiveness of imaging protocols for suspected appendicitis. Pediatrics. https://doi.org/10.1542/peds.2019-1352

16. Di Saverio S, Podda M, De Simone B et al (2020) Diagnosis and treatment of acute appendicitis: 2020 update of the WSES Jerusalem guidelines. World J Emerg Surg 15:1-42. https://doi.org/ 10.1186/s13017-020-00306-3

17. Kularatna M, Lauti M, Haran C, Macfater W (2017) Clinical prediction rules for appendicitis in adults: which is best? World $\mathrm{J}$ Surg 41:1769-1781. https://doi.org/10.1007/s00268-017-3926-6

18. Castro SMMD, Ünlü Ç, Steller EP et al (2012) Evaluation of the appendicitis inflammatory response score for patients with acute appendicitis. World J Surg 36:1540-1545. https://doi.org/10. 1007/s00268-012-1521-4

19. Kollár D, McCartan DP, Bourke M et al (2015) Predicting acute appendicitis? A comparison of the alvarado score, the appendicitis inflammatory response score and clinical assessment. World J Surg 39:104-109. https://doi.org/10.1007/s00268-0142794-6

20. Sammalkorpi HE, Mentula P, Leppäniemi A (2014) A new adult appendicitis score improves diagnostic accuracy of acute appendicitis-a prospective study. BMC Gastroenterol 14:1-7. https://doi.org/10.1186/1471-230X-14-114

21. Malyar A, Singh B, Dar H et al (2015) A comparative study of appendicitis inflammatory response (AIR) score with Alvarado score in diagnosis of acute appendicitis. Balk Mil Med Rev 18:72. https://doi.org/10.5455/bmmr.180876

22. Gudelis M, Lacasta Garcia JD, Trujillano Cabello JJ (2019) Diagnosis of pain in the right Iliac Fossa. A new diagnostic score based on decision-tree and artificial neural network methods. Cirugía Española (English Ed) 97:329-335. https://doi.org/10. 1016/j.cireng.2019.06.002

23. Karami MY, Niakan H, Zadebagheri N et al (2017) Which one is better? Comparison of the acute inflammatory response, Raja Isteri Pengiran Anak Saleha Appendicitis and Alvarado scoring systems. Ann Coloproctol 33:227-231. https://doi.org/10.3393/ ac.2017.33.6.227

24. Yeşiltaş M, Karakaş DÖ, Gökçek B et al (2018) Can alvarado and appendicitis inflammatory response scores evaluate the severity of acute appendicitis? Ulus Travma ve Acil Cerrahi Derg 24:557-562. https://doi.org/10.5505/tjtes.2018.72318

25. Macco S, Vrouenraets BC, de Castro SMM (2016) Evaluation of scoring systems in predicting acute appendicitis in children. Surg (United States) 160:1599-1604. https://doi.org/10.1016/j.surg. 2016.06.023

26. Gudjonsdottir J, Marklund E, Hagander L, Salö M (2020) Clinical prediction scores for pediatric appendicitis. Eur J Pediatr Surg. https://doi.org/10.1055/s-0040-1710534 
27. Scott AJ, Mason SE, arunakirinathan M et al (2015) risk stratification by the appendicitis inflammatory response score to guide decision-making in patients with suspected appendicitis. $\mathrm{Br} \mathbf{J}$ Surg 102:563-572. https://doi.org/10.1002/bjs.9773

28. Andersson M, Rubér M, Ekerfelt C et al (2014) Can new inflammatory markers improve the diagnosis of acute appendicitis? World J Surg 38:2777-2783. https://doi.org/10.1007/ s00268-014-2708-7

29. Di Saverio S, Sibilio A, Giorgini E et al (2014) The NOTA study (non operative treatment for acute appendicitis): Prospective study on the efficacy and safety of antibiotics (amoxicillin and clavulanic acid) for treating patients with right lower quadrant abdominal pain and long-term follow-up of conser. Ann Surg 260:109-117. https://doi.org/10.1097/SLA.0000000000000560

30. March B, Leigh L, Brussius-Coelho $M$ et al (2019) Can CRP velocity in right iliac fossa pain identify patients for intervention?
A prospective observational cohort study. Surgeon 17:284-290. https://doi.org/10.1016/j.surge.2018.08.007

31. Andersson RE (2007) The natural history and traditional management of appendicitis revisited: spontaneous resolution and predominance of prehospital perforations imply that a correct diagnosis is more important than an early diagnosis. World J Surg 31:86-92. https://doi.org/10.1007/s00268-006-0056-y

32. Sterne JAC, White IR, Carlin JB et al (2009) Multiple imputation for missing data in epidemiological and clinical research: Potential and pitfalls. BMJ 339:157-160. https://doi.org/10.1136/ bmj.b2393

Publisher's Note Springer Nature remains neutral with regard to jurisdictional claims in published maps and institutional affiliations. 